\title{
Cobertura do solo em vinhedos modifica os atributos do solo e o estado nutricional das videiras
}

\author{
Soil cover in vineyards modifies soil properties and nutritional status of the vines
}

\section{Duane Heloisa Lehmann ${ }^{1 *}$, Paulo Cezar Cassol ${ }^{1}$, Wagner Sacomori ${ }^{1}$, Ana Karolina Ferreira Teixeira ${ }^{1}$, Álvaro Luiz Mafra ${ }^{1}$, Paulo Roberto Ernani ${ }^{1}$ e Jovani Zalamena ${ }^{2}$}

Recebido em 27/01/2016 / Aceito em 29/07/2016

\section{RESUMO}

O cultivo de cobertura verde em vinhedos protege o solo da erosão e ainda pode ser uma alternativa para o controle do vigor da videira. Assim, o objetivo desse estudo foi avaliar a influência do cultivo de plantas de cobertura do solo de vinhedo nos atributos químicos do solo, na composição foliar e no crescimento de ramos da videira do cultivar Cabernet Sauvignon. As avalições foram realizadas na safra 2013/14, em experimento conduzido a partir de 2009 na região do Planalto Sul Catarinense, onde as condições edafoclimáticas favorecem o excesso de vigor da videira. Os tratamentos compreenderam três tipos de plantas, dois manejos e um controle. As plantas foram a sucessão de anuais, trigo mourisco (Fagopyrum esculentum) e azevém (Lolium multiflorum), a perene festuca (Festuca arundinacea) e as nativas (espontâneas) e os manejos foram roçada com o resíduo cultural distribuído em área total e, com a sua transferência da faixa da linha da videira para a faixa da entrelinha. O controle foi a aplicação de herbicida na faixa da linha e roçada na entrelinha. As amostragens das folhas e do solo foram realizadas nas fases de mudança de cor e de maturação plena da uva. As plantas de cobertura e seu manejo, em geral, não afetaram o $\mathrm{pH}$, nem os teores de $\mathrm{Al}, \mathrm{Ca}$ e $\mathrm{Mg}$ trocáveis no solo, porém as anuais aumentaram o $\mathrm{P}$ extraível na camada $0-5 \mathrm{~cm}$ relativamente à testemunha. Em geral, a espécie perene aumentou o $\mathrm{K}$ extraível relativamente à testemunha nas camadas 5-10 e 10$15 \mathrm{~cm}$ e relativamente às plantas anuais e nativas em todas as camadas. A festuca promoveu menor teor de $\mathrm{Mg}$ nas folhas da videira em relação às plantas anuais e menores teores de $\mathrm{P}$ e $\mathrm{K}$ relativamente aos demais tratamentos e também diminuiu o teor de $\mathrm{N}$ foliar e a massa de ramos da videira em relação à testemunha.
PALAVRAS-CHAVE: Cabernet Sauvignon, adubo verde, atributos do solo, composição foliar.

\section{ABSTRACT}

The cover crop intercropping in vineyards protects the soil from erosion and can be an alternative for controlling the growth of the vine. The aim of this study was to evaluate the changes in the soil's chemical properties, leaf composition and branch growth of Cabernet Sauvignon vine caused by the cover crops in the vineyard. The study was carried in an experiment conducted from 2009 in the highlands of Santa Catarina state, where the soil and climatic conditions favor the excessive growth of the vine. The treatments consisted of three types of cover crops, two management and a control. The cover crops were annual, buckwheat (Fagopyrum esculentum) and ryegrass (Lolium multiflorum), the perennial fescue (Festuca arundinacea) and the native (spontaneous), while the managements were mowed with the crop residue in total area and, with its transfer from the row to the between row of the vine. Samples of leaves and soil were carried out in "veraison" and at end of grape maturation stages, respectively. The cover crops and its management in general did not change the soil $\mathrm{pH}$, or the exchangeable content of $\mathrm{Al}, \mathrm{Ca}$ and $\mathrm{Mg}$, but the annual did increase the available $\mathrm{P}$ content in the $0-5 \mathrm{~cm}$ layer compared to the control. The perennial in general did increase the extractable $\mathrm{K}$ content compared to the control in the 5-10 and 10$15 \mathrm{~cm}$ layers, and compared to the annual and native crops in all of the soil layers. The perennial reduced the leaf contents of $\mathrm{P}$ and $\mathrm{K}$ when compared to other treatments, the $\mathrm{Mg}$ leaf content was compared to the annual and decreased the $\mathrm{N}$ leaf content and the mass of branches when compared to the control treatment.

\footnotetext{
${ }^{1}$ Universidade do Estado de Santa Catarina, Lages, SC, Brasil.

${ }^{2}$ Empresa Brasileira de Pesquisa Agropecuária, Bento Gonçalves, RS, Brasil.

*Autor para correspondência <duaneheloisalehmann@gmail.com>
} 
KEYWORDS: Cabernet Sauvignon, green manure, soil properties, leaf content.

\section{INTRODUÇÃO}

No Brasil, a videira é cultivada do extremo Sul ao Nordeste, porém as regiões de altitude possuem forte potencial para produção de vinhos de qualidade superior, como ocorre no município de São Joaquim, onde as condições climáticas são favoráveis à videira, especialmente pela ocorrência de alta insolação diurna e de noites frias no período de maturação da uva (BORGHEZAN et al. 2014). Assim, a elevada amplitude térmica, com temperaturas noturnas amenas que ocorrem em altitudes superiores a $900 \mathrm{~m}$, fazem com que a maturação fenólica seja mais completa (BORGHEZAN et al. 2014).

$O$ cultivo da videira enxertada com o porta-enxerto Paulsen 1103, em solos com alta disponibilidade de $\mathrm{N}$, promove aumento no vigor dessa frutífera (MAFRA et al. 2011). A alta disponibilidade de $\mathrm{N}$ na região do Planalto Sul Catarinense decorre do acúmulo de matéria orgânica (MO) no solo, a qual é mineralizada mais intensamente pela atividade dos microrganismos do solo. Estes microrganismos são favorecidos pela adição de calcário na implantação do vinhedo, que eleva o $\mathrm{pH}$ e elimina o alumínio tóxico, além de condições favoráveis de umidade e temperatura (CANTARELLA 2007). Com isso, diversos nutrientes ficam mais disponíveis às plantas, principalmente o $\mathrm{N}$, que pode ser absorvido em grande quantidade, já que pode ser encontrado em

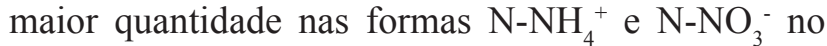
solo (ZALAMENA 2012), favorecendo o crescimento vegetativo da videira.

O excesso de vigor, que também é favorecido pelo caráter vigoroso do porta enxerto Paulsen 1103, produz excesso de ramos e folhas que aumentam o sombreamento no dossel e nas uvas, necessitando assim uma gestão mais intensiva das plantas (LOPES et al. 2008), principalmente, a realização de podas verdes com maior frequência, aumentando os custos de manejo da videira. O sombreamento nos cachos ainda pode acarretar outros problemas, como baixa fecundidade das gemas, diminuição do rendimento, retardamento da maturação e má qualidade dos frutos (WHEELER et al. 2005). Além disso, o sombreamento da planta favorece o ataque de doenças fúngicas (BOTELHO et al. 2004).

Espécies perenes ou anuais de plantas de cobertura do solo, ou mesmo as plantas nativas espontâneas podem ser cultivadas em vinhedos como cobertura verde para ciclagem de nutrientes e proteger a superfície do solo da erosão (DALLA ROSA et al. 2009). Além disso, essas plantas podem promover competição, controlando a disponibilidade de nutrientes e água à videira (PÉREZ-BERMÚDEZ et al. 2016), atuando como alternativa para a redução do excesso de vigor vegetativo dessa frutífera, onde as condições edafoclimáticas são favoráveis à ocorrência desse problema (MONTEIRO \& LOPES 2007). A soma da massa de ramos retirados nas podas da videira representa a intensidade do crescimento vegetativo dessa frutífera e pode ser um indicador do vigor das plantas (KLIEWER \& DOKOOZLIAN 2005).

Neste contexto, realizou-se este trabalho em local de altitude de $1129 \mathrm{~m}$ acima do nível do mar no Sul do Brasil, para avaliar as consequências do cultivo em vinhedo de plantas anuais, perenes e nativas de cobertura verde do solo, avaliando também a influência do manejo dos resíduos dessas plantas nos atributos químicos do solo, nos teores de macronutrientes nas folhas e no crescimento dos ramos da videira.

\section{MATERIAL E MÉTODOS}

Conduziu-se um experimento em vinhedo comercial da vinícola Suzin (latitude 28¹4'10" S, longitude 504'15" W, a 1129 m de altitude) no município de São Joaquim, região do Planalto Sul Catarinense, o qual fora implantado no ano de 2009 e conduzido nos primeiros 3 anos por ZALAMENA (2012), seguido por FERREIRA (2014) na safra 2012/13.

As videiras da cultivar Cabernet Sauvignon, enxertada em porta-enxerto Paulsen 1103 foram plantadas em 2002 com espaçamentos de $1,20 \mathrm{~m}$ entre plantas e 2,90 m entre as filas e conduzidas em sistemas de espaldeira. O solo é classificado como Cambissolo Húmico Distrófico derivado de basalto (EMBRAPA 2006) e o clima é do tipo mesotérmico úmido com verões amenos, $\mathrm{Cfb}$ na classificação de Köppen. Segundo ZALAMENA (2012), os atributos químicos e físicos na época de implantação do experimento apresentavam-se conforme representado na Tabela 1.

Os tratamentos foram três tipos de plantas de cobertura verde do solo em cultivo intercalar com as videiras sob dois manejos e um tratamento testemunha, 
Tabela 1 - Atributos físicos e químicos nas camadas 0-10 cm e 10-20 cm de um Cambissolo Húmico do Planalto Catarinense sob cultivo de videira.

Table 1 - Physical and chemical attributes in 0-10 cm and 10-20 cm layers of Haplumbrept soil planted with vines.

\begin{tabular}{llc}
\hline \multicolumn{1}{c}{ Atributo } & \multicolumn{2}{c}{ Camada } \\
\cline { 2 - 3 } & $0-10 \mathrm{~cm}$ & $10-20 \mathrm{~cm}$ \\
\hline Argila, $\mathrm{g} \mathrm{kg}^{-1(1)}$ & 481 & 570 \\
Silte, $\mathrm{g} \mathrm{kg}^{-1(1)}$ & 367 & 302 \\
Areia, $\mathrm{g} \mathrm{kg}^{-1(1)}$ & 152 & 128 \\
Matéria orgânica, $\mathrm{g} \mathrm{kg}^{-1(2)}$ & 81 & 63 \\
$\mathrm{pH}-\mathrm{H}_{2} 0^{(2)}$ & 6,85 & 5,79 \\
$\mathrm{Al}$ trocável, $\mathrm{cmol}_{\mathrm{c}} \mathrm{dm}^{-3(3)}$ & 0 & 0,17 \\
$\mathrm{Mg}^{(2)}$ trocável, $\mathrm{cmol}_{\mathrm{c}} \mathrm{dm}^{-3(3)}$ & 4,59 & 2,74 \\
$\mathrm{Ca}$ trocável, $\mathrm{cmol}_{\mathrm{c} \mathrm{dm}} \mathrm{dm}^{(3)}$ & 11,82 & 3,88 \\
$\mathrm{P}$ disponível, $\mathrm{mg} \mathrm{dm}^{-3(4)}$ & 6,82 & 1,07 \\
$\mathrm{~K}$ disponível, $\mathrm{mg} \mathrm{dm}^{-3(4)}$ & 436 & 208 \\
\hline
\end{tabular}

Fonte: (ZALAMENA 2012).

Notas: Dados extraídos da tese de doutorado de ZALAMENA (2012). ${ }^{(1)}$ Método da pipeta (EMBRAPA 1997); (2) determinado segundo TEDESCO et al. (1995); ${ }^{(3)}$ Extraído por $\mathrm{KCl} 1 \mathrm{~mol} \mathrm{~L}^{-1}$ (TEDESCO et al. 1995); ${ }^{(4)}$ Extraído por Mehlich 1 (TEDESCO et al. 1995).

constituindo um fatorial $3 \times 2+1$. As plantas de cobertura avaliadas foram uma sucessão de espécies anuais, o trigo mourisco (Fagopyrum esculentum) e o azevém (Lolium multiflorum) (T2 e T3), a espécie perene festuca (Festuca arundinacea) (T4 e T5) e as plantas nativas, ou espontâneas (T6 e T7). Já os manejos testados foram roçada sem a transferência dos resíduos culturais da linha para a entrelinha da videira (st) (T2, T4 e T6) e roçada com essa transferência (ct) (T3, T5 e T7). No tratamento testemunha (T1) as plantas espontâneas foram controladas pela aplicação de herbicida na faixa da linha e por roçada na faixa da entrelinha (prática comum nos vinhedos da região). $\mathrm{O}$ delineamento experimental utilizado foi em blocos casualizados, com quatro repetições, sendo cada parcela formada por 12 plantas úteis distribuídas ao longo de duas linhas de videira, mantendo-se duas plantas e uma linha de videiras como bordaduras.

As espécies anuais receberam duas roçadas e o respectivo manejo de seus resíduos, uma na fase de florescimento e outra no final do ciclo, enquanto as nativas e a festuca receberam quatro roçadas a cada ano. A partir da instalação do experimento (2009), as parcelas foram mantidas seguindo os respectivos tratamentos, conforme o ciclo de semeadura das espécies.

Em fevereiro de 2014, aos 61 meses após a implantação inicial das plantas de cobertura foram coletadas 10 subamostras de solo por parcela em pontos com distância entre $25-50 \mathrm{~cm}$ do caule da videira. A coleta foi realizada com o auxílio de um trado tipo calador, nas camadas de 0-5, 5-10 e 10-15 $\mathrm{cm}$ de profundidade. As amostras foram secas a $50{ }^{\circ} \mathrm{C}$ em estufa com circulação de ar, moídas e peneiradas com malha de $2 \mathrm{~mm}$ de abertura. Foram determinados os seguintes atributos de solo: $\mathrm{pH}$ em $\mathrm{CaCl}_{2} 0,1 \mathrm{~mol}$ $\mathrm{L}^{-1}$; teores de cálcio $(\mathrm{Ca})$ e magnésio $(\mathrm{Mg})$ e alumínio (Al) trocáveis, extraídos com solução neutra de $\mathrm{KCl}$ $1 \mathrm{~mol} \mathrm{~L}^{-1}$, sendo os dois primeiros quantificados por espectrofotometria de absorção atômica e o último por titulação ácido-base; e teores de potássio $(\mathrm{K})$ e fósforo (P) disponíveis, extraídos com solução ácida (Mehlich 1), sendo o primeiro quantificado por fotometria de chama e o segundo por colorimetria.

A amostragem das folhas foi realizada na safra 2013/14 na época denominada "veraison", quando ocorre a viragem de cor e o início do amolecimento das bagas. Retirou-se a folha oposta ao segundo cacho do ramo, a partir da base, porque este em geral apresentou maior qualidade que o primeiro. Coletouse uma folha completa (limbo + pecíolo) de cada lado por planta e esse material foi seco a $65{ }^{\circ} \mathrm{C}$ e moído para ser digerido com $\mathrm{H}_{2} \mathrm{SO}_{4}$ e $\mathrm{H}_{2} \mathrm{O}_{2}$ para obtenção do extrato e em seguida determinou-se os teores de $\mathrm{N}$, $\mathrm{P}, \mathrm{K}, \mathrm{Ca}$ e $\mathrm{Mg}$, seguindo a metodologia descrita por TEDESCO et al. (1995).

O vigor da videira foi avaliado através da massa seca dos ramos retirados nas podas seca e 
verde. A poda seca foi realizada em setembro de 2013, onde se retirou os ramos crescidos da safra anterior, desprovidos de folhas. Em janeiro do ano seguinte quantificou-se a massa seca dos ramos retirados na poda verde, composta por brotações laterais de ramos e folhas verdes.

A análise estatística dos dados coletados tanto da análise do solo quanto das folhas da videira foi efetuada com auxílio do programa SAS (SAS INSTITUTE 2002) através de contrastes ortogonais, comparando-se as variáveis de solo em cada camada separadamente. Foram comparados os seguintes contrastes: contraste $\mathrm{C} 1$ que compara a testemunha (T1) com as plantas de cobertura anuais (T2 e T3); contraste $\mathrm{C} 2$ que compara a testemunha (T1) com a planta perene (T4 e T5); contraste C3 que compara a testemunha (T1) com as plantas nativas (T6 e T7); contraste $\mathrm{C} 4$ que compara as anuais (T2 e T3) com a perene (T4 e T5); contraste $\mathrm{C} 5$ que compara a perene (T4 e T5) com as nativas (T6 e T7) e o contraste C6 que compara os dois manejos das plantas de cobertura (T2, T4 e T6 com T3, T5 e T7). A associação entre os atributos químicos do solo e a composição química do tecido foi avaliada por correlações de Pearson. Os dados da produção de massa seca dos ramos retirados na poda seca e verde foram também submetidos à análise de variância, sendo as médias comparadas pelo teste de Tukey $(\mathrm{p}<0,05)$, também com o auxílio do programa SAS (SAS INTITUTE 2002).

\section{RESULTADOS E DISCUSSÃO}

O pH em água do solo variou de 5,5 a 6,8 (Tabela $2)$, evidenciando valores mais elevados na camada superficial $(0-5 \mathrm{~cm})$, diminuindo com a profundidade. Em geral, não houve efeito dos tratamentos no $\mathrm{pH}$ do solo, confirmando a expectativa que o cultivo das plantas avaliadas não promove mudança de $\mathrm{pH}$ no solo em relação à testemunha, sobretudo em solo com alto poder tampão de $\mathrm{pH}$ como o empregado nesse estudo. Na camada 10-15 cm, houve diferença nos contrastes da testemunha com as plantas de cobertura, tanto anuais, quanto perenes e nativas, sugerindo que o cultivo dessas plantas pode aumentar o $\mathrm{pH}$ do solo. Porém, considera-se que o significado agronômico dessa diferença é inexpressivo ao sistema de cultivo, conforme proposto por KAMINSKI et al. (2005). Assim, a diferença foi atribuída à desuniformidade da distribuição e, ou incorporação da calagem realizada anteriormente na área experimental, o que já fora constatado por ZALAMENA (2012) que, após 27 meses do início dos cultivos das plantas de cobertura do mesmo experimento, encontrou valores de $\mathrm{pH}$ semelhantes ao do atual estudo, embora sem diferir dos demais tratamentos na mesma camada.

Outros autores, também relataram que as plantas de cobertura em geral não alteram o $\mathrm{pH}$ do solo (PAVAN et al. 1986, CUNHA et al. 2011, SOUZA 2012). Entretanto, na fase inicial do atual estudo, ZALAMENA (2012) observou aumento de $\mathrm{pH}$ nas camadas até $10 \mathrm{~cm}$ de profundidade do solo sob cultivo de plantas anuais (sucessão moha + azevém e trigo mourisco + aveia branca) em relação à testemunha. A adição de resíduos de plantas de cobertura pode aumentar o $\mathrm{pH}$ do solo devido à neutralização dos íons $\mathrm{H}^{+}$e/ou a complexação do Al trocável por subprodutos da decomposição desses resíduos vegetais (MIYAZAWA et al. 1993, AMARAL et al. 2004, NASCIMENTO et al. 2003). Outra possibilidade são as reações de troca de ligantes entre ânions orgânicos e os grupos $\mathrm{OH}$ - superficiais dos óxidos de Fe e Al (FRANCHINI et al. 2001, BRESSAN et al. 2013).

Deve-se considerar que os estudos que detectaram efeitos de plantas de cobertura no $\mathrm{pH}$ do solo foram em geral realizados em situações de lavouras, ou equivalentes, onde as quantidades de resíduos culturais aplicados e/ou reciclados no solo foram expressivamente superiores aos valores desse atual estudo.

Os cultivos de cobertura do solo e seu manejo não afetaram o teor do Al trocável no solo (Tabela 2). Destaca-se que esse atributo ocorreu em baixos teores, o que se deve ao $\mathrm{pH}$ ser maior que 5,5, situação que reduz drasticamente a solubilidade do Al. Entretanto, PAVAN et al. (1986) em experimento a campo em lavoura cafeeira verificaram que os teores de Al trocável diminuíram com a manutenção da cobertura verde no solo, caracterizada por cultivo de gramíneas na linha de plantio, com ceifa do material nas entrelinhas.

As plantas anuais promoveram maior teor de P extraível no solo do que a testemunha na camada de $0-5 \mathrm{~cm}$, principalmente no tratamento sem transferência dos resíduos (Tabela 2). Entretanto, essa foi a única diferença significativa entre os tratamentos contrastados. O maior teor de $\mathrm{P}$ encontrado na camada 0-5 cm, nos tratamentos com as plantas anuais, provavelmente resultou da absorção do nutriente pelas culturas e consequente ciclagem de formas de 
Tabela 2 - Valores de $\mathrm{pH}$ e teores de $\mathrm{Al}$ trocável $\left(\mathrm{cmol}_{\mathrm{c}} \mathrm{dm}^{-3}\right), \mathrm{P}$ e, $\mathrm{K}$ disponíveis e de Ca e $\mathrm{Mg}$ trocáveis em Cambissolo Húmico, e significância das comparações de médias por contrastes, após 61 meses de cultivo de plantas de cobertura consorciadas com videiras Cabernet Sauvignon, em São Joaquim,SC.

Table 2 - Soil $\mathrm{pH}$ and content of exchangeables $\mathrm{Al}, \mathrm{Ca}$ and $\mathrm{Mg}\left(\mathrm{cmol}_{\mathrm{c}} \mathrm{dm}^{-3}\right)$ and availables $P$ and $\mathrm{K}$ of Haplumbrept soil and significance of mean comparisons by contrasts, after 61 months of intercropping cover crops with Cabernet Sauvignon vines in São Joaquim, SC.

\begin{tabular}{|c|c|c|c|c|c|c|c|c|c|}
\hline \multirow[b]{2}{*}{ Variáveis } & \multirow{2}{*}{$\begin{array}{c}\text { Camada } \\
\mathrm{cm}\end{array}$} & \multicolumn{8}{|c|}{ Tratamentos } \\
\hline & & $\mathrm{T} 1$ & $\mathrm{~T} 2$ & $\mathrm{~T} 3$ & $\mathrm{~T} 4$ & T5 & T6 & $\mathrm{T} 7$ & CV $(\%)$ \\
\hline $\mathrm{pH}$ em & 0 a 5 & 6,4 & 6,7 & 6,8 & 6,8 & 6,8 & 6,7 & 6,4 & 4,1 \\
\hline \multirow[t]{2}{*}{ água } & 5 a 10 & 6,1 & 6,2 & 6,4 & 6,6 & 6,5 & 6,4 & 6,0 & 6,7 \\
\hline & 10 a 15 & 5,5 & 6,0 & 5,9 & 6,2 & 6,3 & 6,2 & 6,0 & 5,5 \\
\hline \multirow{3}{*}{$\begin{array}{c}\mathrm{Al}^{+3} \\
\left(\mathrm{cmol}_{\mathrm{c}} \mathrm{dm}^{-3}\right)\end{array}$} & 0 a 5 & 0,5 & 0,1 & 0,6 & $-0,1$ & 0,2 & 0,4 & 0,2 & 140,6 \\
\hline & 5 a 10 & 0,4 & 0,1 & 0,3 & 0,2 & 0,3 & 0,6 & 0,5 & 99,0 \\
\hline & 10 a 15 & 0,5 & 0,7 & 0,4 & 0,3 & 0,4 & 0,3 & 0,4 & 60,4 \\
\hline \multirow{3}{*}{$\begin{array}{c}\mathrm{P} \\
\text { disponível } \\
\left(\mathrm{mg} \mathrm{dm}^{-3}\right)\end{array}$} & 0 a 5 & 20,6 & 33,8 & 28,6 & 25,3 & 34,8 & 24,6 & 20,5 & 38,0 \\
\hline & 5 a 10 & 8,5 & 4,5 & 6,1 & 5,7 & 5,8 & 5,9 & 4,7 & 58,9 \\
\hline & 10 a 15 & 2,7 & 3,8 & 3,4 & 1,1 & 2,1 & 2,4 & 1,7 & 65,7 \\
\hline \multirow{3}{*}{$\begin{array}{c}\mathrm{K} \\
\text { trocável } \\
\left(\mathrm{mg} \mathrm{dm}^{-3}\right)\end{array}$} & 0 a 5 & 155,0 & 125,8 & 135,5 & 211,0 & 193,5 & 161,3 & 123,8 & 26,0 \\
\hline & 5 a 10 & 61,8 & 49,8 & 51,5 & 120,4 & 75,3 & 49,0 & 40,8 & 26,6 \\
\hline & 10 a 15 & 36,8 & 37,3 & 33,8 & 52,6 & 40,0 & 34,0 & 25,8 & 16,1 \\
\hline \multirow{3}{*}{$\begin{array}{c}\mathrm{Ca} \\
\text { disponível } \\
\left(\mathrm{mg} \mathrm{dm}^{-3}\right)\end{array}$} & 0 a 5 & 11,96 & 12,62 & 12,56 & 30,04 & 12,98 & 12,91 & 11,7 & 6,33 \\
\hline & 5 a 10 & 8,53 & 9 & 9,64 & 9,53 & 9,72 & 9,84 & 8,43 & 16,5 \\
\hline & 10 a 15 & 5,41 & 6,58 & 6,96 & 6,62 & 6,8 & 7,28 & 6,38 & 22,3 \\
\hline \multirow{3}{*}{$\begin{array}{c}\mathrm{Mg} \\
\text { trocável } \\
\left(\mathrm{mg} \mathrm{dm}^{-3}\right)\end{array}$} & 0 a 5 & 6,2 & 6,9 & 7,0 & 7,2 & 7,4 & 7,2 & 6,6 & 8,6 \\
\hline & 5 a 10 & 5,6 & 5,7 & 6,1 & 6,1 & 6,0 & 5,9 & 5,1 & 13,5 \\
\hline & 10 a 15 & 4,0 & 4,3 & 4,8 & 4,6 & 4,6 & 4,5 & 4,2 & 18,7 \\
\hline \multicolumn{10}{|c|}{ Contraste entre os tratamentos } \\
\hline \multirow{5}{*}{$\begin{array}{l}\text { pH em } \\
\text { água }\end{array}$} & & Test. $\mathrm{X}$ & Test. $\mathrm{X}$ & Test. $\mathrm{X}$ & Anuais $\mathrm{X}$ & Per. $\mathrm{X}$ & Sem 2 & Com & \\
\hline & & Anuais & Perene & Nativa & Per. & Nat. & $\mathrm{Ma}$ & ejo & \\
\hline & 0 a 5 & ns & ns & ns & $\mathrm{ns}$ & ns & & & \\
\hline & 5 a 10 & ns & ns & ns & ns & ns & & & \\
\hline & 10 a 15 & $*$ & $* *$ & $*$ & ns & ns & & & \\
\hline \multirow{3}{*}{$\begin{array}{c}\mathrm{Al}^{+3} \\
\left(\mathrm{cmol}_{\mathrm{c}} \mathrm{dm}^{-3}\right)\end{array}$} & 0 a 5 & $\mathrm{~ns}$ & $\mathrm{~ns}$ & $\mathrm{~ns}$ & $\mathrm{~ns}$ & $\mathrm{~ns}$ & & & \\
\hline & 5 a 10 & $\mathrm{~ns}$ & ns & $\mathrm{ns}$ & ns & $\mathrm{ns}$ & & & \\
\hline & 10 a 15 & ns & ns & $\mathrm{ns}$ & ns & ns & & & \\
\hline \multirow{3}{*}{$\begin{array}{c}\mathrm{P} \\
\text { disponível } \\
\left(\mathrm{mg} \mathrm{dm}^{-3}\right) \\
\end{array}$} & 0 a 5 & $*$ & $\mathrm{~ns}$ & $\mathrm{~ns}$ & $\mathrm{~ns}$ & $\mathrm{~ns}$ & & & \\
\hline & 5 a 10 & ns & ns & $\mathrm{ns}$ & ns & $\mathrm{ns}$ & & & \\
\hline & 10 a 15 & ns & ns & $\mathrm{ns}$ & ns & ns & & & \\
\hline \multirow{3}{*}{$\begin{array}{c}\mathrm{K} \\
\text { trocável } \\
\left(\mathrm{mg} \mathrm{dm}^{-3}\right)\end{array}$} & 0 a 5 & $\mathrm{~ns}$ & $\mathrm{~ns}$ & $\mathrm{~ns}$ & $* *$ & $*$ & & & \\
\hline & 5 a 10 & ns & $* *$ & $\mathrm{~ns}$ & $* * *$ & $* * *$ & & & \\
\hline & 10 a 15 & ns & $*$ & ns & $* *$ & $* * *$ & & & \\
\hline \multirow{3}{*}{$\begin{array}{c}\mathrm{Ca} \\
\text { disponível } \\
\left(\mathrm{mg} \mathrm{dm}^{-3}\right) \\
\end{array}$} & 0 a 5 & $\mathrm{~ns}$ & $\mathrm{~ns}$ & $\mathrm{~ns}$ & $\mathrm{~ns}$ & $\mathrm{~ns}$ & & & \\
\hline & 5 a 10 & $\mathrm{~ns}$ & ns & ns & ns & ns & & & \\
\hline & 10 a 15 & $\mathrm{~ns}$ & $\mathrm{~ns}$ & $\mathrm{~ns}$ & ns & ns & & & \\
\hline \multirow{3}{*}{$\begin{array}{c}\mathrm{Mg} \\
\text { trocável } \\
\left(\mathrm{mg} \mathrm{dm}^{-3}\right)\end{array}$} & 0 a 5 & $\mathrm{~ns}$ & $*$ & $\mathrm{~ns}$ & $\mathrm{~ns}$ & $\mathrm{~ns}$ & & & \\
\hline & 5 a 10 & ns & ns & ns & ns & ns & & & \\
\hline & 10 a 15 & ns & ns & ns & ns & ns & & & \\
\hline
\end{tabular}

Nota: T1: Testemunha; T2: (trigo mourisco + azevém), roçada; T3: (trigo mourisco + azevém), roçada com transferência; T4: (festuca), roçada; T5: (festuca), roçado com transferência; T6: (nativa), roçada; T7: (nativa), roçada com transferência do resíduo cultural para a entrelinha da videira. Os símbolos *, **, *** indicam que houve diferença significativa entre os tratamentos que formam o contraste a $\mathrm{p}<0,05 ; \mathrm{p}<0,01$ e $\mathrm{p}<0,001$, respectivamente. ns $=$ contrastes não significativos. 
P disponíveis retiradas de camadas mais profundas e depositadas na superfície do solo, quando da decomposição dos seus resíduos (RHEINHEIMER \& ANGHINONI 2001). Além disso, no tratamento testemunha as plantas nativas são dessecadas na linha da videira e no tratamento com as anuais estas são roçadas, ficando o sistema radicular ativo, o que faz com que haja renovação das raízes e consequente maior ciclagem de nutrientes.

A transferência do resíduo da linha para a entrelinha das videiras não afetou a quantidade de $\mathrm{P}$ do solo, indicando que a transferência do resíduo não fez com que o teor deste nutriente diminuísse na faixa linha da cultura. MORETI et al. (2007) também não detectaram efeito das coberturas verdes no teor de P extraível do solo. Entretanto, SOUZA (2012) ao avaliar a influência de plantas de cobertura (milheto, crotalária, guandu, mucuna, pousio, milheto + guandu, milheto + crotalária e milheto + mucuna-preta) sobre os atributos químicos, observou aumento do $\mathrm{P}$ extraível em camadas de 0 até $10 \mathrm{~cm}$ de profundidade.

Comparando-se com o tratamento testemunha, a festuca aumentou o teor de $\mathrm{K}$ do solo em aproximadamente $50 \%$ onde o resíduo foi mantido na linha da videira, entretanto, onde houve a transferência do resíduo, o aumento foi de cerca de $15 \%$ (Tabela 2). A festuca também resultou em teor de $K$ no solo maior do que as plantas anuais em todas as camadas, indicando que aquela espécie perene possui maior capacidade de ciclagem desse nutriente no solo. $\mathrm{Na}$ camada mais superficial $(0-5 \mathrm{~cm})$, nos tratamentos onde não houve a transferência dos resíduos, o teor de $\mathrm{K}$ no solo com a festuca foi cerca de $60 \%$ maior do que com as anuais, enquanto, nos tratamentos em que essa transferência foi realizada essa diferença chegou a 70\%. Isso também evidencia a maior capacidade da festuca de ciclagem e disponibilização de $\mathrm{K}$ no solo.

Comparando-se a festuca com as nativas, também se constatam diferenças significativas nos valores de $\mathrm{K}$ extraível em todas as camadas. As nativas apresentaram menores teores deste nutriente no solo, mostrando que possuem potencial para serem utilizadas como cobertura verde de parreirais para competir com as videiras em solos com disponibilidade excessiva de $\mathrm{K}$, tendo comportamento semelhante às plantas anuais.

Em relação ao manejo, a transferência dos resíduos da linha à entrelinha resultou em teores de $\mathrm{K}$ extraível menores na camada de $5-10 \mathrm{~cm}$, no conjunto das plantas de cobertura avaliadas. Resultado diferente foi encontrado por ZALAMENA (2012) que observou que a quantidade de nutriente transferida da linha para a entrelinha, no período de duas safras avaliadas, não foi suficiente para que houvesse redução significativa no teor de K extraível do solo.

STEINER et al. (2011) ao avaliarem o efeito de coberturas associado e três fontes de adubação (mineral, orgânica e organomineral) em Latossolo Vermelho eutroférrico sob plantio direto, observaram que o sistema de rotação da cultura com plantas de cobertura foi o que apresentou os maiores teores de $\mathrm{K}$ no solo. Esta maior concentração de K na superfície do solo é relacionada com a atuação do sistema radicular das plantas que promovem ciclagem deste elemento no solo, pois a absorção de $\mathrm{K}$ pelas raízes mais profundas pode ser transferida para a camada mais superficial. Este retorno do K contido na parte aérea vegetal ao solo também foi demonstrado por SILVA \& RITCHEY (1982), onde se verificou que a água da chuva lixiviou o $K$ da parte aérea das plantas de milho assim que as plantas entraram em senescência, pois foram observados maiores teores de $\mathrm{K}$ no solo na projeção da planta em comparação ao centro das entrelinhas do milho.

Os teores de $\mathrm{Ca}$ e $\mathrm{Mg}$ trocáveis foram em geral semelhantes em todos os tratamentos, concordando com resultados de DALLA ROSA et al. (2009), embora esses autores observaram maiores teores de $\mathrm{Ca}$ e $\mathrm{Mg}$ trocáveis quando as plantas de cobertura foram dessecadas. Porém, comparativamente com os teores na época de implantação do experimento (Tabela 1), observa-se um aumento destes elementos na camada $0-10 \mathrm{~cm}$. O teor de $\mathrm{Mg}$ foi diferente apenas no contraste da testemunha com a festuca na camada de $0-5 \mathrm{~cm}$, onde essa planta perene promoveu maior teor deste nutriente no solo.

$\mathrm{O}$ teor de $\mathrm{N}$ nas folhas de videira (Tabela 3) variou entre 14 - $17 \mathrm{~g} \mathrm{~kg}^{-1}$, valores que se enquadram em classe de teores abaixo do normal, conforme CQFS-RS/SC (2004). As videiras consorciadas com a festuca foram as que apresentaram menor teor de $\mathrm{N}$ foliar. FERREIRA (2014) também constatou redução no teor de $\mathrm{N}$ foliar das videiras consorciadas com a perene festuca, nas safras 2011/12 e 2012/13, onde nos consórcios com as plantas anuais, as videiras apresentaram teores de $\mathrm{N}$ bastante semelhantes com o das consorciadas com o tratamento testemunha. Isso mostra que as plantas de cobertura consorciadas com a videira, em especial a festuca, disputam por $\mathrm{N}$ inorgânico e água no solo (CELETTE et al. 2009), 
reduzindo a disponibilidade deste nutriente no solo e consequentemente para a videira (CELETTE \& GARY 2013).

As sucessões de plantas anuais apresentaram maior teor de $\mathrm{N}$ nas folhas da videira em relação à festuca (Tabela 3). CELETTE et al. (2009) e ZALAMENA et al. (2013b) também encontraram resultados semelhantes, o que, segundo eles, se justifica pela demora no desenvolvimento radicular das anuais combinado ao curto período que permanecem no solo em relação à festuca e com isso absorvem menor quantidade de $\mathrm{N}$ que essa espécie perene, ficando esse com maior disponibilidade no solo para as videiras.

$\mathrm{O}$ teor de $\mathrm{P}$ nas folhas $\left(1,2-2,0 \mathrm{~g} \mathrm{~kg}^{-1}\right)$ enquadrou-se em faixa normal segundo a CQFS-RS/ $\mathrm{SC}$ (2004). Ambos os tratamentos com as plantas de cobertura cultivadas demonstraram que a utilização do consórcio aumentou a disponibilidade deste nutriente para a videira em relação ao tratamento testemunha. Sendo que o consórcio com a espécie festuca apresentou maior quantidade deste nutriente na folha da videira, seguido das nativas e anuais.

$\mathrm{O}$ teor de $\mathrm{K}$ nas folhas $\left(9,28\right.$ a $\left.14,5 \mathrm{~g} \mathrm{~kg}^{-1}\right)$ também se enquadra em faixa normal segundo a CQFS-RS/SC (2004). Houve diferença significativa no contraste testemunha versus festuca, onde as videiras consorciadas com a planta perene apresentaram maiores teores do nutriente nas folhas. O mesmo ocorreu ao contrastar as anuais com a festuca e essas com as nativas, tendo as videiras do tratamento com a festuca maiores teores deste nutriente.

Os aumentos nos teores de $\mathrm{P}$ e $\mathrm{K}$ foliares da videira encontrados neste estudo em geral concordam com o observado por FERREIRA (2014) porém, contrastam com os valores encontrados por ZALAMENA (2012), que constatou diminuição significativa destes nutrientes nas folhas de videiras dos tratamentos com planta de cobertura. Isso sugere que com o tempo as plantas de cobertura podem disponibilizar estes nutrientes para a cultura, a qual não vem sendo adubada com fertilizantes nos últimos 4 anos.

$\mathrm{O}$ teor de Ca nas folhas da videira não foi afetado pelas plantas de cobertura de solo e seu manejo. Isso se explica pelo alto teor de Ca trocável existente no solo, o que possibilita farta disponibilidade desse

Tabela 3 - Teores de N, P, K, Ca e Mg, em g kg-1, nas folhas da videira Cabernet Sauvignon, e significância das comparações de médias por contrastes, após 61 meses de cultivo de plantas de cobertura consorciadas com essa videira, em Cambissolo Húmico em São Joaquim, SC.

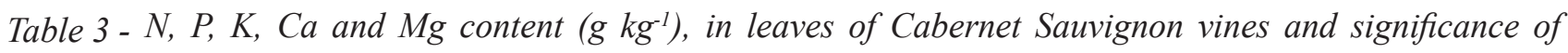
mean comparisons by contrasts, after 61 months of intercropping cover crops with that vines in a Haplumbrept soil in São Joaquim, SC.

\begin{tabular}{|c|c|c|c|c|c|c|c|c|}
\hline \multirow[b]{2}{*}{ Elemento } & \multicolumn{8}{|c|}{ Tratamentos } \\
\hline & $\mathrm{T} 1$ & $\mathrm{~T} 2$ & $\mathrm{~T} 3$ & $\mathrm{~T} 4$ & T5 & $\mathrm{T} 6$ & $\mathrm{~T} 7$ & $\mathrm{CV}(\%)$ \\
\hline $\mathrm{N}$ & 16,49 & 15,27 & 16,32 & 14,36 & 14,96 & 15 & 16,54 & 7,79 \\
\hline $\mathrm{P}$ & 1,18 & 1,34 & 1,36 & 1,89 & 1,98 & 1,41 & 1,65 & 12,35 \\
\hline $\mathrm{K}$ & 9,56 & 10,45 & 9,97 & 14,54 & 14,44 & 10,04 & 9,28 & 15,57 \\
\hline $\mathrm{Ca}$ & 7,36 & 7,63 & 8,87 & 7,16 & 7,97 & 7,74 & 7,87 & 11,18 \\
\hline \multirow[t]{4}{*}{$\mathrm{Mg}$} & 4,25 & 4,79 & 5,26 & 3,88 & 3,90 & 4,84 & 4,73 & 20,15 \\
\hline & \multicolumn{8}{|c|}{ Contraste entre os tratamentos } \\
\hline & Test. X & Test. $\mathrm{X}$ & Test. $\mathrm{X}$ & Anual X & Per. $\mathrm{X}$ & Sem x Com & & \\
\hline & Anuais & Perene & Nativa & Perene & Nativa & Manejo & & \\
\hline $\mathrm{N}$ & ns & $*$ & $\mathrm{~ns}$ & ns & $\mathrm{ns}$ & ns & & \\
\hline $\mathrm{P}$ & $\mathrm{ns}$ & $* * *$ & $* *$ & $* * *$ & $* *$ & $\mathrm{~ns}$ & & \\
\hline $\mathrm{K}$ & $\mathrm{ns}$ & $* * *$ & $\mathrm{~ns}$ & $* * *$ & $* * *$ & $\mathrm{~ns}$ & & \\
\hline $\mathrm{Ca}$ & $\mathrm{ns}$ & $\mathrm{ns}$ & $\mathrm{ns}$ & ns & $\mathrm{ns}$ & $\mathrm{ns}$ & & \\
\hline $\mathrm{Mg}$ & $\mathrm{ns}$ & $\mathrm{ns}$ & $\mathrm{ns}$ & $*$ & $\mathrm{~ns}$ & $\mathrm{~ns}$ & & \\
\hline
\end{tabular}

Nota: T1: testemunha; T2: (trigo mourisco + azevém), roçada; T3: (trigo mourisco + azevém), roçada com transferência; T4: (festuca), roçada; T5: (festuca), roçada com transferência; T6: (nativa), roçada; T7: (nativa), roçada com transferência do resíduo cultural para a entre linha da videira. *, **, *** houve diferença significativa entre os tratamentos que formam o contraste a $p<0,05 ; p<0,01$ e $p<0,001$, respectivamente. $n s=$ contrastes não significativos. 
elemento em todos os tratamentos.

Entretanto, ZALAMENA (2012) detectou teores de $\mathrm{Ca}$ maiores, tanto no tratamento com as plantas anuais, quanto com a espécie festuca em relação à testemunha, em folhas da videira coletadas na fase de mudança de cor. Entretanto, nas folhas coleadas na floração ZALAMENA (2012) observou tendência inversa, ou seja, os teores foram menores nos tratamentos com plantas anuais ou perene, indicando falta de consistência de tais resultados. Outra possibilidade é que os resultados refletem a variação na competição oferecida pelas plantas de cobertura que pode ter se concentrado em período de intenso crescimento, coincidente com a fase de floração da videira.

Quanto ao $\mathrm{Mg}$ nas folhas houve diferença significativa unicamente no contraste das anuais com a festuca, tendo essa causado maior teor deste nutriente, o que tem caracterizado uma maior capacidade da festuca em manter crescimento e consequente maior taxa de absorção de $\mathrm{Mg}$ em período onde há grande sombreamento causado pela videira. ZALAMENA (2012) também observou na safra 2010/11 que teores de Mg nas folhas da videira foram semelhantes entre os diversos tratamentos com plantas de cobertura, exceto pela espécie festuca ter causado menores valores de $\mathrm{Mg}$ nas folhas da videira em relação às plantas anuais.

A massa seca (MS) dos ramos da poda seca variou entre 733 a $1170 \mathrm{~kg} \mathrm{ha}^{-1}$ (Figura 1). A festuca, sem a transferência dos resíduos para a entrelinha, foi o único tratamento que diferiu significativamente da testemunha, das anuais (com transferência do resíduo) e das nativas (sem transferência do resíduo), apresentando, em média, valor $29 \%$ menor de MS dos ramos da videira do que esses tratamentos. Isso mostra que o cultivo intercalar da festuca pode, com o passar do tempo, reduzir o vigor da videira, confirmando a tendência dos resultados relatados por ZALAMENA (2012) na safra 2010/11, o qual também observou redução na produção de MS dos ramos da videira nos tratamentos onde houve o cultivo intercalar da festuca. Esse efeito da festuca também foi demonstrado por CELETTE et al. (2005). Já CARVALHO (2014) verificou aumento na produção de massa dos ramos da videira da cultivar Bordô nas safras 2011/12 e 2012/12 sob cultivo intercalar de amendoim forrageiro como cobertura,

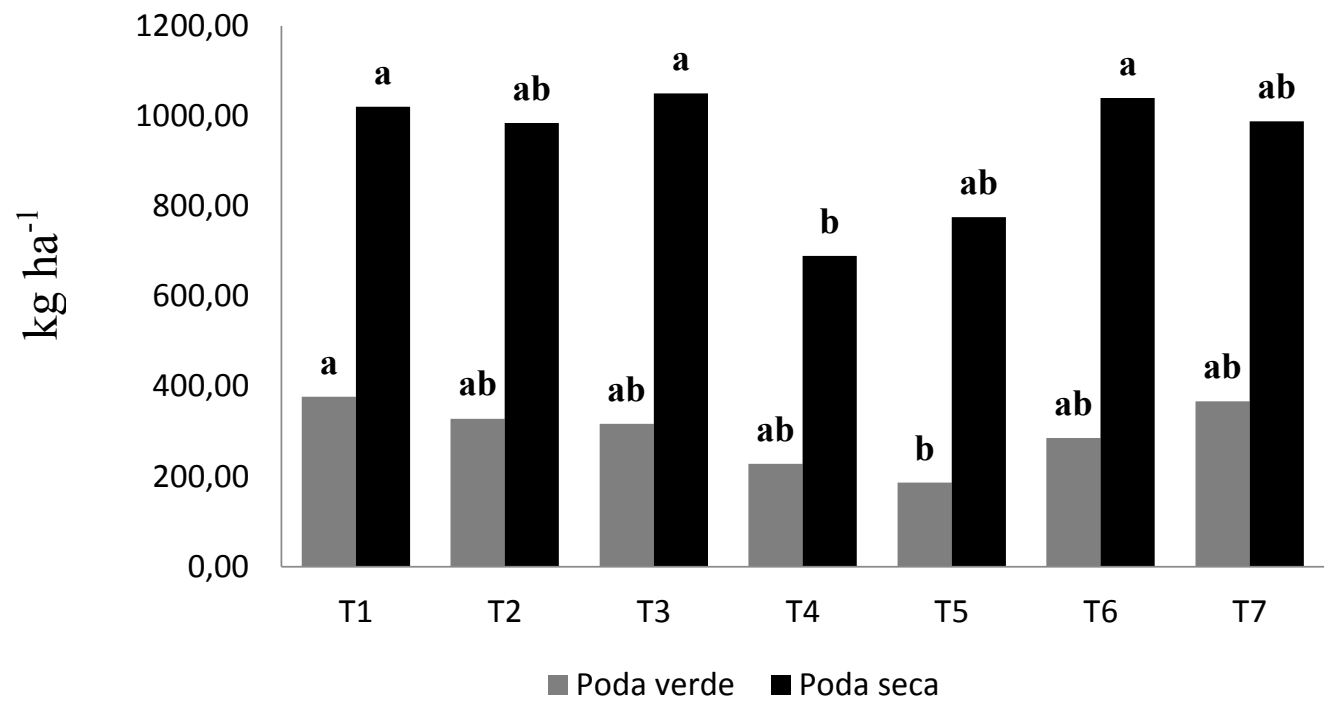

Nota: T1: testemunha; T2: (trigo mourisco + azevém), roçada; T3: (trigo mourisco + azevém), roçada com transferência; T4: (festuca), roçada; T5: (festuca), roçada com transferência; T6: (nativa), roçada; T7: (nativa), roçada com transferência do resíduo cultural para a entre linha da videira. Letras minúsculas diferentes indicam diferença pelo teste de Tukey a 5\%.

Figura 1 - Massa de ramos e folhas retirados na poda verde da safra 2013/14 e massa seca (MS) de ramos da poda seca (2013) de videiras Cabernet Sauvignon enxertadas sobre P-1103, após 61 meses de cultivo de plantas de cobertura consorciadas com essa videira, em Cambissolo Húmico distrófico em São Joaquim, SC.

Figure 1 - Mass of branches and leaves taken in summer pruning of the crop and dry matter (DM) branches of dry pruning (2013) Cabernet Sauvignon vines grafted on P-1103, after 61 months of intercropping cover crops with that vines in a Haplumbrept soil in São Joaquim, SC. 
comparativamente a tratamentos com solo limpo e sem adubação nitrogenada. Nesse caso, a planta de cobertura é leguminosa e aporta nitrogênio ao solo e as videiras respondem ao aumento de nutrição com $\mathrm{N}$ tanto na vegetação como na produção.

O tipo de solo também influencia nos aspectos qualitativos e quantitativos da produção de uvas destinadas à vinificação, conforme observado por CHAVARRIA et al. (2011) em experimento em vinhedo da cultivar Cabernet Sauvignon cultivada em três tipos de solos (Argissolo Bruno-acizentado, Planossolo Háplico e Neossolo Regolítico). Esse autor concluiu que, dentre os solos estudados, o Neossolo Regolítico foi o mais promissor para a obtenção de vinhos finos de qualidade, pois resultou em menor crescimento vegetativo, mas favoreceu aspectos qualitativos da uva. Este comportamento foi atribuído à menor disponibilidade de água nesse solo restringindo a disponibilidade hídrica à videira, provocando menor crescimento e rendimento, mas maiores teores de taninos e índice de polifenóis totais.

$\mathrm{O}$ menor crescimento de ramos de videira sob cultivo intercalar de festuca também foi evidenciado na poda verde (Figura 1), onde o consórcio com a transferência do resíduo resultou em produção de MS de $186 \mathrm{~kg} \mathrm{ha}^{-1}$, valor 50\% menor em comparação à testemunha que teve $376 \mathrm{~kg} \mathrm{ha}^{-1}$, embora não diferiu no tratamento sem a transferência, o qual foi semelhante à produção de MS da testemunha e dos demais consórcios com a videira. O manejo dos resíduos culturais, com ou sem a transferência da linha à entrelinha, não afetou a MS da poda verde.

FERREIRA (2014) na safra 2012/13 também observou menor crescimento de ramos em videiras sob cultivo intercalar da planta perene festuca, manejada com transferência dos resíduos culturais, comparativamente ao tratamento com solo descoberto na faixa da linha, indicando que a presença da festuca possibilita maior equilíbrio entre produção e vigor das videiras. Assim, denota-se que cultivo intercalar da espécie de cobertura verde festuca com a videira Cabernet Sauvignon, sobre o porta enxerto Paulsen 1103 em Cambissolo Húmico do Planalto sul Catarinense diminui a disponibilidade de $\mathrm{N}$ a essa frutífera e, em consequência reduz o crescimento vegetativo podendo ser indicado como alternativa para diminuir o vigor de videiras. Entretanto, destacase que há carência de estudos de longa duração para avaliar o desempenho do cultivo de plantas de cobertura intercaladas com a videira e o risco que possam ocasionar ao esgotamento das reservas da cultura.

\section{CONCLUSÃO}

Os atributos do solo $\mathrm{pH}$ em água, $\mathrm{P}$ extraível e Ca e $\mathrm{Mg}$ trocáveis em geral não são afetadas pelo cultivo intercalar de plantas de cobertura do solo com as videiras.

A espécie perene festuca em cultivo intercalar às videiras aumenta o teor de $\mathrm{K}$ extraível do solo e diminui os teores de $\mathrm{N}$ e $\mathrm{Mg}$ nas folhas da videira.

$\mathrm{O}$ cultivo intercalar da festuca, manejada sem a transferência dos resíduos para a entrelinha, diminui a massa seca dos ramos da poda seca da videira em relação ao solo limpo por dessecação química das plantas espontâneas na faixa da linha de plantio das videiras.

\section{REFERÊNCIAS}

AMARAL AS et al. 2004. Resíduos de plantas de cobertura e mobilidade dos produtos da dissolução do calcário aplicado na superfície do solo. Revista Brasileira de Ciência do Solo 28:115-123.

BORGHEZAN M et al. 2014. Phenology and vegetative growth in a new production region of grapevines: case study in São Joaquim, Santa Catarina, Southern Brazil. Open Journal of Ecology 4:321-335.

BOTELHO RV et al. 2004. Efeitos do paclobutrazol na fertilidade de gemas e no crescimento dos ramos de videiras cv. rubi. Revista Brasileira de Fruticultura 26:345-347.

BRESSAN SB et al. 2013. Plantas de cobertura e qualidade química de Latossolo Amarelo sob plantio direto no cerrado maranhense. Revista Brasileira de Engenharia Agrícola e Ambiental 17:371-378.

CANTARELLA H. 2007. Nitrogênio. In: NOVAIS RF et al. (eds) Fertilidade do Solo. Viçosa. Sociedade Brasileira de Ciência do Solo, p. 379-440.

CARVALHO JFC. 2014. Desenvolvimento da videira e composição química dos frutos: relação com a cobertura do solo. Tese (Doutorado em Ciências). Piracicaba: ESALQ/ USP. $101 \mathrm{f}$.

CELETTE $\mathrm{F}$ et al. 2005. Belowground interactions in a vine Vitis vinifera L. -tall fescue Festuca arundinacea Shreb. Intercropping system: water relations and growth. Plant Soil 276:205-217.

CELETTE F et al. 2009. Competition for nitrogen in an unfertilized intercropping system: The case of an association of grapevine and grass cover in a Mediterranean climate. European Journal of Agronomy 30:41-51.

CELETTE F \& GARY C. 2013. Dynamics of water and nitrogen stress along the grapevine cycle as affected by 
cover cropping. European Journal of Agronomy 45:142152.

CQFS - COMISSÃO DE QUÍMICA E FERTILIDADE DO SOLO - SC/RS. 2004. Manual de adubação e de calagem para Estados do Rio Grande do Sul e de Santa Catarina. 10. ed. Porto Alegre. Sociedade Brasileira de Ciência do Solo - Núcleo Regional Sul. 400p.

CHAVARRIA $G$ et al. 2011. Relações hídricas, rendimento e compostos fenólicos de uvas Cabernet Sauvignon em três tipos de solo. Bragantia 70:481-487.

CUNHA EQ et al. 2011. Atributos químicos de solo sob produção orgânica influenciados pelo preparo e por plantas de cobertura. Revista Brasileira de Engenharia Agrícola e Ambiental 15:1021-1029.

DALLA ROSA J et al. 2009. Atributos químicos do solo e produtividade de videiras alterados pelo manejo de coberturas verdes na Serra Gaúcha. Revista Brasileira de Ciência do Solo 33:1-6.

EMBRAPA-CNPS. 1997. Manual de métodos de análise de solos. Rio de Janeiro. 212p.

EMBRAPA. 2006. Centro Nacional de Pesquisa de Solos. Sistema Brasileiro de Classificação de solos. 2.ed. 306p. FERREIRA AKT. 2014. Produtividade e qualidade de uva vinífera com cultivo intercalar de plantas de cobertura do solo. Dissertação (Mestrado em Ciência do Solo). Lages. UDESC/CAV. 73p.

FRANCHINI JC et al. 2001. Rapid transformations of plant water-soluble organic compounds in relation to cation mobilization in an acid Oxisol. Plant Soil 231:55-63.

KAMINSKI et al. 2005. Eficiência da calagem superficial e incorporada precedendo o sistema plantio direto em um Argissolo sob pastagem natural. Revista Brasileira de Ciência do Solo 29:573-580.

KLIEWER WM \& DOKOOZLIAN NK. 2005. Leaf area/crop weight ratios of grapevines: influence on fruit composition and wine quality. American Journal of Enology and Viticulture 56:170-181.

LOPES CM et al. 2008. Cover cropping in a sloping nonirrigated vineyard: ii - Effects on vegetative growth, yield, berry and wine quality of 'Cabernet Sauvignon' grapevines. Ciência e Técnica Vitivinícola 23:37-43.

MAFRA SMH et al. 2011. Atributos químicos do solo e estado nutricional de videira Cabernet Sauvignon (Vitis vinifera L.) na Serra Catarinense. Revista de Ciências Agroveterinárias 10:44-53.

MIYAZAWA M et al. 1993. Efeito de material vegetal na acidez do solo. Revista Brasileira de Ciência do Solo 17:411- 416.

MONTEIRO A \& LOPES CM. 2007. Influence of cover crop on water use and performance of vineyard in Mediterranean Portugal. Agriculture, Ecosystems and Environmen 121:336-342.

MORETI D et al. 2007. Atributos químicos de um Latossolo Vermelho sob diferentes sistemas de preparo, adubações e plantas de cobertura. Revista Brasileira de Ciência do Solo
$31: 167-175$.

NASCIMENTO JT et al. 2003. Efeito de leguminosas nas características químicas e matéria orgânica de um solo degradado. Revista Brasileira de Engenharia Agrícola e Ambiental 7:457-462.

PAVAN MA et al. 1986. Manejo da cobertura do solo para formação e produção de uma lavoura cafeeira. I. Influência na fertilidade do solo. Pesquisa Agropecuária Brasileira 21:187-192.

PÉREZ-BERMÚDEZ et al. 2016. Cover crops and pruning in Bobal and Tempranillo vineyards have little influence on grapevine nutrition. Scientia Agricola 73:260-265.

RHEINHEIMER DS \& ANGHINONI I. 2001. Distribuição do fósforo inorgânico em sistemas de manejo de solo. Pesquisa Agropecuária Brasileira 36:151-160.

SAS INSTITUTE. 2002. Getting started with the SAS learning edition. Cary: SAS Institute. 200p.

SILVA JE \& RITCHEY KD. 1982. Acumulação diferencial de potássio em Oxissolos devido a lavagem do nutriente das plantas de milho para o solo. Revista Brasileira de Ciência do Solo 6:183-188.

SOUZA MFP. 2012. Influência de plantas de cobertura e doses de fósforo nos atributos químicos e atividade microbiana do solo. Dissertação (Mestrado em Agronomia). Ilha Solteira:UNESP. 87f.

STEINER F et al. 2011. Atributos químicos do solo em diferentes sistemas de culturas e fontes de adubação. Global Science and Technology 4:16-28.

TEDESCO MJ et al. 1995. Análise de solo, plantas e outros materiais. Porto Alegre. UFRGS-FA - Departamento de Solos. 174p.

WHEELER SJ et al. 2005. Vineyard floor management improves wine quality in highly vigorous Vitis vinifera 'Cabernet Sauvignon' in New Zealand. New Zeal. Journal of Crop and Horticultural Science 33:317-328.

ZALAMENA J. 2012. Plantas de cobertura na redução do vigor da videira em solo com alto teor de matéria orgânica. Tese (Doutorado em Manejo do Solo). Lages. UDESC/ CAV. 73f.

ZALAMENA et al. 2013b. Estado nutricional, vigor e produção em videiras cultivadas com plantas de cobertura. Revista Brasileira de Fruticultura 35:1190-1200. 